\title{
URBANISMO Y LITORAL: LA GESTIÓN DE LAS ZONAS COSTERAS EN ANDALUCÍA Y PRINCIPADO DE ASTURIAS ${ }^{1}$
}

\section{URBAN PLANNING AND LITORAL: THE COASTAL ZONES MANAGEMENT IN ANDALUCÍA AND PRINCIPADO DE ASTURIAS}

\author{
CONSTANZA-BELÉn SÁNCHEZ GARCÍA \\ Abogada urbanista \\ constanzasanchezgarcia@gmail.com
}

\begin{abstract}
Resumen:
El presente trabajo aborda la regulación del litoral en nuestro país, concretamente en las Comunidades Autónomas de Andalucía y Principado de Asturias. Se pretende hacer una comparación entre dos formas de ordenar y proteger el litoral opuestas geográficamente pero muy similares en sus fines y objetivos. Comenzando por los antecedentes históricos y el marco legislativo en el que se desarrollan, tanto a nivel europeo como estatal, se analizan a lo largo del texto las diferentes propuestas que uno y otro gobierno autonómico han llevado a cabo para la gestión de las zonas costeras.
\end{abstract}

Palabras clave: Gestión integrada de zonas costeras, ordenación del territorio, dominio público marítimo-terrestre, servidumbre de protección, deslinde, concesiones.

\begin{abstract}
:
The present work deals with the regulation of the coast in our country, specifically in the Autonomous Communities of Andalucía and Principado de Asturias. It is intended to make a comparison between two forms of ordering and protecting the coast, opposited geographically but very similar in their aims and objectives. Starting from the historical background and the legislative framework in which they are developed, both european and state, the different proposals that one and another regional government have carried out for the management of coastal zones are analyzed throughout the text.
\end{abstract}

Keywords: Integrated coastal zones management, land management, maritime-land public domain, right of protection, demarcation, licences.

Sumario: 1. Introducción. 2. Legislación aplicable. 2.1. La regulación de las costas en la Unión Europea. 2.2. Legislación estatal: evolución. 2.2.a. La Ley de Costas de 1988. 2.2.b. La Ley 2/2013 de Protección y Uso Sostenible del Litoral. 2.3. La regulación del litoral por las Comunidades Autónomas. 3. El litoral andaluz. 3.1. Legislación de la Comunidad Autónoma de Andalucía en materia de costas. Los instrumentos de la ordenación del territorio y su relación con el litoral. 3.2. El Plan de Protección del Corredor Litoral de Andalucía. 3.3. Un ejemplo de la dicotomía desarrollo urbanístico-

\footnotetext{
${ }^{1}$ Este artículo tiene origen en el Trabajo Fin de Máster de Abogacía de la Universidad de Málaga realizado por la autora en el curso 2016/2017, bajo la dirección de la Profesora Doctora Da María Remedios Zamora Roselló, obteniendo tras su defensa ante el Tribunal una calificación de Matrícula de Honor (10).

REJIE Nueva época: Revista Jurídica de Investigación e Innovación Educativa Núm.20, Junio 2019, pp. 61-88 [En línea] http://www.revistas.uma.es/index.php/rejie Recibido: diciembre 2018 Aceptado: marzo 2019
} 
protección del litoral: el caso del hotel de El Algarrobico. 4. El litoral asturiano. 4.1. Legislación de la Comunidad Autónoma del Principado de Asturias en materia de costas. Los instrumentos de la ordenación del territorio y su relación con el litoral. 4.2. El Plan Territorial Especial de Ordenación del Litoral de Asturias. 4.3. Un ejemplo de la dicotomía desarrollo urbanístico-protección del litoral: el caso del hotel Kaype. 5. Conclusiones. Bibliografía.

\section{Índice de abreviaturas:}

- GIZC: Gestión Integrada de las Zonas Costeras.

- CEMAT: Conferencia Europea de Ministros responsables de la Ordenación del Territorio (en francés: Conférence du Conseil de l'Europe des Ministres responsables de l'Aménagement du Territoire).

- RGC: Reglamento General de Costas.

- POTA: Plan de Ordenación del Territorio de Andalucía.

- PPCLA: Plan de Protección del Corredor Litoral de Andalucía.

- PORN: Plan de Ordenación de los Recursos Naturales.

- PRUG: Plan Rector del Uso y Gestión.

- JCA: Juzgado de lo Contencioso-Administrativo.

- TSJA: Tribunal Superior de Justicia de Andalucía.

- TROTU: Texto Refundido de las disposiciones vigentes en materia de Ordenación del Territorio y Urbanismo.

- DROT: Directrices Regionales de Ordenación del Territorio.

- DSOTFC: Directrices Subregionales de Ordenación del Territorio para la Franja Costera.

- POLA: Plan Territorial Especial de Ordenación del Litoral Asturiano.

- DSOTAC: Directrices Subregionales del Área Central.

- PESC: Plan Territorial Especial del Suelo No Urbanizable de Costas.

- CUOTA: Comisión de Urbanismo y Ordenación del Territorio del Principado de Asturias.

\section{Introducción.}

Para hablar de litoral es imprescindible comenzar hablando del mar. El medio marino, incluyendo en dicho concepto tanto las aguas como otros recursos que en él se encuentran, constituye una unidad natural y también jurídica que ocupa más del $70 \%$ de la superficie del planeta. Su gran extensión y presencia no hace sino magnificar la importancia que su cuidado y preservación tienen en la vida humana. Confluyen sobre él implicaciones medioambientales, económicas, políticas, sociales y hasta culturales, desde el ámbito internacional hasta la básica delimitación regional de las diferentes zonas costeras. Esta materia se ve legislada, por tanto, en el ámbito del Derecho Internacional y, como decíamos, al más elemental nivel territorial, que en nuestro país no es otro que el de las Comunidades Autónomas.

En España, un país rodeado prácticamente en su totalidad por agua, cobra especial importancia la protección del medio marino y del litoral adyacente, debido a tanto a los recursos materiales que nos pueden ofrecer (pesca, industria o energías renovables, entre otros muchos), como a los inmateriales, fundamentalmente su función de reclamo para el numerosísimo turismo que nos visita. Se trata de espacios naturales con una recuperación muy lenta en caso de agresión. Daños que se producen por causa de, entre 
otros factores, su constante uso por la población, el turismo, la pesca... así como por la delicadeza inherente de los elementos que los componen. Las zonas costeras están entre las áreas más vulnerables al cambio climático y a los desastres naturales: inundaciones, subida del nivel del mar, erosión... Se trata de riesgos con un impacto de gran alcance y consecuencias devastadoras que ya están cambiando las vidas y la subsistencia de los seres humanos, los animales y todas las especies vegetales que en ellas habitan.

Es por todas estas razones que se hace imprescindible su protección desde los órganos gubernativos. La misma debe implantarse tanto de manera directa, con leyes medioambientales que impongan derechos y deberes con respecto a estos espacios, como también indirectamente. Ejemplo de ésta última es la normativa urbanística, puesto que la ordenación del territorio y su posterior desarrollo afectan de manera clara y evidente al entorno natural en el que se aplican.

El motivo de realizar el presente trabajo es llevar a cabo una comparación entre los diferentes modelos reguladores del litoral que se aplican en nuestras Autonomías. Quien suscribe es asturiana y lleva más de 10 años viviendo en Andalucía, de manera que he considerado oportuno e interesante realizar la comparación entre ambas Comunidades Autónomas: las dos poseen un litoral extenso en proporción a su territorio, y una gran parte de su economía depende directa y exclusivamente del estado de sus zonas costeras y del mar adyacente a las mismas.

Se trata, a pesar de las similitudes que en un principio existen, de dos puntos de vista muy diferentes. Asturias, con una costa abrupta y fundamentalmente dedicada a la pesca, aunque en evolución hacia el uso turístico. Andalucía, también pesquera pero con prácticamente la totalidad de su extensión cubierta por zonas sobreexplotadas por el turismo. Diferentes modelos de uso, pero sin embargo, un mismo objetivo en el ámbito costero: el equilibrio entre la protección del litoral y su utilización para fines generales y particulares.

\section{Legislación aplicable.}

\subsection{La regulación de las costas en la Unión Europea.}

Desde la Unión Europea consideran que el bienestar de la población y la viabilidad económica de las zonas costeras depende del estado medioambiental de las mismas, por lo que es esencial hacer uso de herramientas de gestión a largo plazo, como la Gestión Integrada de las Zonas Costeras (GIZC), así como asegurar que la estrategia a desarrollar sea global y coordinada entre todos los sectores implicados. Esta es una conclusión lógica y acertada, que ha tardado mucho tiempo en verbalizarse. La explotación de nuestras costas no es algo que haya sucedido sólo de los años ochenta en adelante, sino que lleva ocurriendo desde mucho antes.

La GIZC impulsada desde la Unión Europea tiene como objetivo la aplicación coordinada de las diferentes políticas que afectan a la zona litoral y a todas aquellas actividades que están relacionadas con el medio, tales como la pesca, el flete, el turismo o la protección de la naturaleza. Se trata de un sistema de gestión desde la perspectiva del "enfoque por ecosistemas"2 que cubre todo el ciclo de recopilación de información,

\footnotetext{
${ }^{2}$ El enfoque por ecosistemas es una estrategia para la gestión integrada de tierras, extensiones de aguas y recursos vivos por la que se promueve la conservación y utilización sostenible de modo equitativo. Surgió como principio fundamental en la aplicación del Convenio sobre la Diversidad Biológica de las Naciones Unidas. En su segunda reunión, celebrada en Yakarta en 1995, la Conferencia de las Partes lo adoptó
} 
planificación, toma de decisiones, llevanza y supervisión del cumplimiento de la legalidad. Se señala desde Bruselas la importancia que tiene el involucrar en cada uno de estos procesos a todos los sectores interesados, de manera que se garantice un respaldo generalizado para la puesta en práctica de las estrategias de gestión ${ }^{3}$.

En el ámbito comunitario se han llevado a cabo distintas iniciativas para implantar una política europea de GIZC. En 1973 comienza esta andadura con la adopción en el Consejo de Europa de una Resolución sobre la Protección de las Zonas Costeras ${ }^{4}$. Diez años más tarde, bajo el auspicio del Consejo de Europa, la Conferencia Europea de Ministros Responsables de la Ordenación del Territorio (CEMAT) trabajó para la elaboración de la Carta Europea de Ordenación del Territorio, firmada en Torremolinos en mayo de 1983. En referencia a las zonas costeras se señala un objetivo particular: "el desarrollo del turismo de masas en Europa y de los transportes, así como la industrialización de las zonas costeras, de las islas y del mar, hacen necesarias políticas específicas para estas regiones, con el objetivo de asegurarles un desarrollo equilibrado y una urbanización coordinada, teniendo en cuenta las exigencias dictadas por la protección del entorno natural y las características regionales." 5 .

La Cumbre de la Tierra de las Naciones Unidas celebrada en Río de Janeiro en 1992 fue un impulso más al desarrollo de la política europea de GIZC propiamente dicha. En el Capítulo 10 de la Agenda 216 , el documento resultante de dichas sesiones, se recoge la necesidad de una gestión del territorio sostenible e integrada. Las conclusiones hacían un llamamiento específico a los países costeros para que pusieran en marcha estrategias de GIC $^{7}$. Coincidentemente, el Consejo Europeo había adoptado, el 25 de febrero de 1992, la "Resolución relativa a la futura política comunitaria sobre la zona costera europea", y el 6 de mayo de 1994, la "Resolución relativa a una estrategia comunitaria de gestión integrada de la zona costera". En sendas resoluciones el Consejo Europeo reconocía el enfoque integrado como un aspecto muy importante para afrontar los retos relativos a la gestión del litoral, e instaba a la Comisión a dar un paso adelante en la elaboración de propuestas para pasar a la acción en este ámbito ${ }^{8}$.

Siguiendo estas sugerencias, de 1996 a 1999 la Comisión Europea llevó a cabo un Programa Demostración sobre la GIZC para recopilar información técnica y estimular un amplio debate entre los variados actores implicados en el planeamiento, gestión y uso de las zonas costeras europeas. Con base en las experiencias y resultados la Comisión aprobó a su finalización dos documentos: la "Comunicación de la Comisión Europea al Consejo y al Parlamento Europeo sobre la Gestión Integrada de las Zonas

como principal marco para las actividades del Convenio. "Directrices del Convenio sobre Diversidad Biológica de las Naciones Unidas" (2004), págs. 3 y 6.

${ }^{3}$ Extraído de la página web de la Comisión Europea relativa a la Gestión Integrada de las Zonas Costeras: http://ec.europa.eu/environment/iczm/index_eu.htm

4 "Resolution (73) 29 on the Protection of Coastal Areas", adopted by the Committee of Ministers on 26 October 1973, at the 225th meeting of the Ministers' Deputies.

5 "Charte Européenne de l'aménagement du territoire" ("Charte de Torremolinos"), pág. 10.

${ }^{6}$ La Agenda 21, la Declaración de Río sobre el Medio Ambiente y el Desarrollo y la Declaración de Principios para la Gestión Sostenible de los Bosques se firmaron por más de 178 países en la Conferencia de Naciones Unidas sobre el Medio Ambiente y el Desarrollo (UNCED), que tuvo lugar en Río de Janeiro, Brasil, entre el 3 y el 14 de junio de 1992. La Agenda 21 contiene un plan de acción exhaustivo que ha sido adoptado por múltiples organizaciones del Sistema de Naciones Unidas y Gobiernos.

${ }^{7}$ Bases de acción y líneas de acción recogidas en el Capítulo 17 de dicha Agenda 21: "Protección de los Océanos y de los Mares de todo tipo, incluidos los mares cerrados y semicerrados, y de las Zonas Costeras, y protección, utilización racional y desarrollo de sus recursos vivos".

${ }^{8}$ Extraído de la página web de la Comisión Europea relativa a la Gestión Integrada de las Zonas Costeras: http://ec.europa.eu/environment/iczm/background.htm 
Costeras: una Estrategia para Europa"9 y la "Recomendación del Parlamento Europeo y del Consejo, de 30 de mayo de 2002, sobre la aplicación de la Gestión Integrada de las Zonas Costeras en Europa" $"$.

Más recientemente, la Comisión Europea adoptó el 12 de marzo de 2013 la "Propuesta de Directiva por la que se establece un marco para la ordenación del espacio marítimo y la gestión integrada de las costas"11. En este instrumento se requiere a los Estados Miembros para que establezcan estrategias de gestión del litoral que refuercen los principios y elementos expuestos por la Recomendación de 30 de mayo de 2002 y en el Protocolo del Convenio de Barcelona relativo a la GIZC, ratificado por la Unión en $2010^{12}$. Entre los requerimientos encontramos la coordinación de las políticas relevantes que afecten al litoral. Usar un único instrumento base para armonizar todos los demás redactados a nivel nacional incrementa la seguridad jurídica y económica para los posibles inversores y reduce la carga administrativa de los gobiernos, a la vez que se preservan los ecosistemas existentes de la manera más efectiva ${ }^{13}$.

Mientras que en las políticas y directrices que se implantan desde la Unión Europea se aprecia sin lugar a dudas la nítida intención de proteger por encima de todo el medio ambiente, en las sucesivas normativas instauradas en nuestro país la referencia principal a la hora de legislar sobre el litoral son los efectos económicos que se puedan derivar de su aplicación ${ }^{14}$, tal y como podemos observar en el siguiente apartado.

\subsection{Legislación estatal: evolución.}

La primera Ley de Costas de nuestro país se promulgó en el año 1969, en un contexto histórico y social evidentemente marcado por el desarrollo económico acelerado que sufría España en esa década. El turismo y la prematura urbanización de las costas estaban en su máximo apogeo, circunstancias que se vieron plenamente reflejadas en el contenido de la Ley. A pesar de este bagaje, en la norma de 1969 se recogían los primeros y tímidos avances hacia la declaración de bien demanial del litoral español, así como la ordenación de aquellas titularidades privadas constituidas con anterioridad a la ley. En el artículo primero se hace mención expresa a estos derechos legalmente adquiridos y a su permanencia a pesar de la declaración de dominio público. Estos terrenos quedaban sujetos, eso sí, a ciertas servidumbres. La armonía entre la titularidad

\footnotetext{
${ }^{9}$ Comunicación de la Comisión al Consejo y al Parlamento Europeo sobre la gestión integrada de las zonas costeras: una estrategia para Europa (COM/2000/0547 final).

${ }^{10}$ Recomendación del Parlamento Europeo y del Consejo, de 30 de mayo de 2002, sobre la aplicación de la gestión integrada de las zonas costeras en Europa. Diario Oficial de Unión Europea $n^{\circ}$ L 148 de 06/06/2002, págs. $24-27$.

${ }^{11}$ Dictamen del Comité de las Regiones - Propuesta de Directiva para la ordenación del espacio marítimo y la gestión integrada de las costas. Diario Oficial n ${ }^{\circ}$ C 356 de 05/12/2013, pág. 124. Como consecuencia de esta Propuesta se ha promulgado la Directiva 2014/89/UE del Parlamento Europeo y del Consejo, de 23 de julio, por la que se establece un marco para la ordenación del espacio marítimo.

${ }^{12}$ En 1975 dieciséis países mediterráneos y la Comunidad Económica Europea adoptaron el Plan de Acción para la Protección y el Desarrollo de la cuenca del Mediterráneo. Como marco jurídico de sus actividades se adopta el 16 de febrero de 1976 el Convenio para la Protección del mar Mediterráneo contra la Contaminación, el llamado "Convenio de Barcelona". En 2008, en la Conferencia del PAM celebrada en Almería, se aprobó el Protocolo relativo a la Gestión Integrada de las Zonas Costeras del Mediterráneo. Dicho Protocolo fue ratificado por España en 2010 y entró en vigor en el año 2011.

${ }^{13}$ Extraído de la página web de la Comisión Europea relativa a la Política Europea sobre Zonas Costeras: http://ec.europa.eu/environment/iczm/prop_iczm.htm

${ }^{14}$ ZAMORA ROSELLÓ, M.R., (2014): "La protección y uso sostenible del litoral español a la vista de las previsiones comunitarias", Actualidad Administrativa, IX Congreso de la Asociación Española de Profesores de Derecho Administrativo, págs. 1 - 2.
} 
pública y el uso privado de las costas estaba empezando a gestarse, sin embargo, era un camino que sólo estaba comenzando.

Una década más tarde, la Constitución de 1978 declaraba sin ambages el carácter demanial de las zonas costeras de nuestro país. De hecho, son los únicos bienes que aparecen señalados directamente como tales en la Constitución. Se trata, sin lugar a dudas, de un avance en la protección de las zonas costeras de nuestro país. Sin embargo, no se producen cambios inmediatos en el litoral ya que el propio precepto constitucional hace referencia a un "futuro desarrollo legal" específico, que no se producirá hasta diez años más tarde con la promulgación de la Ley de Costas de 1988. En el artículo 45 de la Constitución nos encontramos, además, con la otra vertiente que venimos contraponiendo al desarrollo urbanístico, la obligación de protección del medio ambiente $^{15}$ de los poderes públicos y el derecho de todos los ciudadanos a su disfrute. En los artículos 148 y 149 nos encontramos con el reparto competencial de la materia: las Comunidades Autónomas pueden asumir competencias en materia de gestión de la protección del medio ambiente; mientras que el Estado tiene competencia exclusiva en lo referente a la legislación básica sobre esta materia. Con este esquema competencial ya establecido se unía un motivo más a la necesidad acuciante de renovar la obsoleta Ley de Costas de 1969: establecer una base legal para las posibles regulaciones autonómicas que los gobiernos de las Comunidades Autónomas pudiesen elaborar a partir de ese momento para la ordenación y protección de sus áreas de costa.

\section{2.a. Ley de Costas de 1988.}

Pese a la urgente necesidad de una nueva Ley sobre el litoral hubieron de transcurrir dos legislaturas para que, finalmente, el 28 de julio de 1988, se promulgara la Ley 22/1988 de Costas. Para dar cobertura a los riesgos que amenazaban la costa española y, simultáneamente, conservar los derechos colectivos de los ciudadanos al uso y disfrute de la zona litoral, la Ley de Costas de 1988 impone un modelo regulador novedoso, pero aún tímido, que tiene en cuenta tanto los intereses generales propios de un dominio público como los particulares que en él se puedan desarrollar. Hasta ese momento ninguna de las normas reguladoras había señalado sus fines últimos, posiblemente porque se trataba, hasta entonces, de un espacio natural que no se consideraba prioritario, ni en su conservación, ni en su desarrollo ${ }^{16}$. Sin embargo, podemos afirmar que Ley de 1988 tenía un enfoque más ambiental que cualquiera de sus predecesoras. Prueba de ello son las variadas disposiciones de contenido medioambiental que nos encontramos a lo largo de su articulado ${ }^{17}$, como por ejemplo, exigencias ambientales para proyectos y obras o la regulación de los vertidos ${ }^{18}$.

Entre las numerosas novedades incluidas en la Ley de 1988 destacaban la incorporación de otros bienes naturales, como los acantilados o las dunas, al dominio público marítimo-terrestre, y la ampliación de la extensión de aquellos que ya eran considerados

\footnotetext{
${ }^{15} \mathrm{Al}$ respecto de la vertiente medioambiental incluida en la legislación de ordenación territorial: RANDO BURGOS, E., (2018): "La atención al medio ambiente desde la ordenación del territorio: una visión general desde el marco legislativo autonómico", Actualidad Jurídica Ambiental, ISSN-e 1989-5666, №. 81, 2018, págs. $121-156$.

16 NÚÑEZ LOZANO, M.C. (2015): "El Litoral de Andalucía. Norma y Naturaleza.", Servicio de Publicaciones de la Universidad de Huelva, pág. 261.

${ }^{17}$ Ver artículos 32, 42, 44, o 56 a 62, entre otros, de la Ley de Costas de 1988.

${ }^{18}$ SANZ LARRUGA, F.J. (2000): "La protección ambiental del litoral español. Hacia una gestión sostenible e integrada de las zonas costeras.", Anuario da Facultade de Dereito da Universidade da Coruña, págs. $459-485$.
} 
demaniales en la anterior versión. Igualmente, se incluye como nuevo espacio del dominio público la denominada "ribera del mar": bien demanial que incluiría la zona marítimo-terrestre, los espacios húmedos tales como albuferas o marismas que pudiesen existir, la playa y las dunas. Es a partir del límite interior de la ribera desde donde se comenzarían a contar los metros que quedarían afectados por la servidumbre correspondiente: de protección, de tránsito o de acceso al mar.

Pero la gran novedad y el punto álgido de la nueva regulación del litoral que imponía la Ley de 1988 era la situación en la que quedaban las edificaciones y propiedades privadas existentes en la zona marítimo-terrestre. La norma excluía expresamente la posibilidad de hubiera propiedad privada en bienes demaniales, incluso aunque éste fuera un derecho adquirido legalmente. Es el punto central de la regularización del litoral: la disyuntiva entre la determinación del dominio público y el uso de las costas. Para intentar darle una solución se estableció un régimen transitorio consistente en la expropiación y posterior transformación de esos derechos legalmente adquiridos en concesiones de ocupación y aprovechamiento por una duración concreta en función del origen de los primigenios derechos de propiedad sustituidos. Al pasar a ser titulares de una concesión administrativa, los dueños de estas fincas y edificaciones dejaban de ser propietarios de las mismas, sin que por ello se procediese a abonarles ningún tipo de indemnización tal y como sucede en el caso de procedimientos expropiatorios, similares en gran medida a esta situación, pues se trata de terrenos de propiedad privada que pasan a titularidad pública. Evidentemente, el alto valor del metro cuadrado en las zonas costeras no ayudó a que la balanza se inclinase por esta solución.

Al respecto precisamente de la falta de indemnización a los propietarios afectados, conviene señalar cómo se pronunciaba la sentencia del Tribunal Constitucional $149 / 1991^{19}$, la cual resolvía sobre el recurso de inconstitucionalidad interpuesto por varias Comunidades Autónomas y 50 Diputados contra varios preceptos y disposiciones de la Ley de Costas de 1988. Dicha sentencia, en su Fundamento Jurídico $8^{\circ}$, considera, muy acertadamente a nuestro entender, que las concesiones otorgadas a los propietarios de terrenos en dominio público marítimo-terrestre constituían una indemnización suficiente por la pérdida de sus titularidades: "Si la expropiación se opera precisamente por la transformación de la propiedad en concesión, el valor económico de ésta no puede ser entendido sino como compensación, determinada ope legis por la privación del título dominical." En referencia a la suficiencia de la indemnización: "La singularidad de las propiedades a las que la norma se aplica, ya antes comentada, de una parte, el mantenimiento aunque sea a título distinto pero por un prolongado plazo, de los derechos de uso y disfrute que los mismos propietarios tenían de la otra, y la consideración, en fin, de que en todo caso esos bienes habrían de quedar sujetos, aun de haberse mantenido en manos privadas, a las limitaciones dimanantes de su enclave en el dominio público, hacen imposible entender que la indemnización ofrecida, dado el valor económico sustancial de ese derecho de ocupación y aprovechamiento del demanio durante sesenta años y sin pago de canon alguno, no represente, desde el punto de vista del juicio abstracto que corresponde a este Tribunal, un equivalente del derecho del que se priva a sus anteriores titulares". El razonamiento del Tribunal es lógico, puesto que los titulares de estos terrenos públicos ciertamente habían perdido la propiedad, pero seguían pudiendo disfrutar de estos especiales lugares sin pago de canon o concesión alguna. Sin embargo, no deja de ser incoherente con el sentido protector de la normativa costera, que no se optara por la opción expropiatoria habitual

\footnotetext{
${ }^{19}$ Ver sentencia número 149/1991, de 4 de julio, del Pleno del Tribunal Constitucional.
} 
eliminando cualquier uso particular del demanio público costero.

Consecuentemente, el hecho de que los propietarios que habían adquirido sus terrenos de manera totalmente legal antes de la entrada en vigor de la ley tuvieran que perder su titularidad en favor del Estado se interpretó por una parte de la doctrina como una aplicación retroactiva de la ley. Hemos de señalar que consideramos totalmente correcta esta interpretación: despojar a los dueños de las fincas de sus propiedades no deja de ser una vulneración de la seguridad jurídica. Habían adquirido sus terrenos con anterioridad a la norma, razón por la cual se debería haber optado por el común procedimiento expropiatorio. Pero los perjuicios para los propietarios de fincas en áreas de dominio público-marítimo terrestre no terminaban con la desposesión de sus terrenos, sino que también veían cercenadas sus posibilidades de proteger sus viviendas o edificaciones. Se impedía que los particulares realizaran obras de mejora, reparación o consolidación en sus edificaciones puesto que éstas se encontraban situadas en dominio público. Que se permitiera a los propietarios ocupar sus fincas durante treinta, o incluso sesenta años y, sin embargo, no pudieran realizar las obras propias de refuerzo o protección de las edificaciones no deja de ser una contradicción en las intenciones de la norma.

Desde el punto de vista ambiental tampoco se apreciaba un futuro más halagüeño con la instauración del régimen concesional. Tal y como señala NÚÑEZ LOZANO ${ }^{20}$, en la práctica poco se iba a diferenciar el uso que de los terrenos haría el nuevo concesionario del uso que, a título de propietario, hacía con anterioridad a la Ley de 1988. Ni que decir tiene que la extensión de las concesiones por sesenta años no viene a colaborar en absoluto al cambio en el paisaje litoral, ni por desgracia, a su protección.

Este régimen transitorio fue recibido, como era previsible, con intranquilidad por los propietarios, pero también por las entidades locales costeras, que, en gran medida, procedieron a reclasificar el suelo que se encontraba en situación de no urbanizable para que se transformara en urbanizable, con planeamiento parcial aprobado, o directamente en suelo urbano. Así, en aplicación de lo previsto en la Disposición Transitoria Tercera de la Ley de Costas, la extensión del área de servidumbre de protección se quedaba en una franja de veinte metros de ancho (la previa establecida por la Ley de 1969), y aquellas propiedades, usos y edificaciones existentes no sufrirían modificaciones.

Como hemos comentado con anterioridad en este apartado, la Ley de 1988 fue demasiado temerosa en sus prescripciones. Su elaboración llegaba tarde al tren del desarrollo inmobiliario y urbanístico del país, por lo que, a pesar de sus buenas intenciones, solucionaba en escasa medida los daños que ya se habían hecho al litoral español. Límites al éxito de la norma de 1988, además de su propio articulado en ocasiones demasiado generoso con el uso privativo del dominio público, fueron las comentadas reclasificaciones del suelo realizadas por los municipios y la complejidad de la ejecución de los deslindes, para los que ni siquiera se establecía plazo de realización en la propia norma ${ }^{21}$. Otro factor que se sumaba al exiguo éxito de la regulación del litoral promulgada en 1988 fue la escasa asignación presupuestaria destinada a poner en marcha sus disposiciones. Esta circunstancia continúa afectando hoy día a la efectividad de las normas que se aplican a la zona costera. Aunque hemos

\footnotetext{
${ }^{20}$ NÚÑ̃Z LOZANO, M.C., loc. cit, pág. 267.

${ }^{21}$ A 31 de diciembre de 2017 aún quedaban Comunidades Autónomas con kilómetros de su costa sin deslindar. Es el caso de Málaga (88\%), Vizcaya (86\%) o Huelva (81\%). Información extraída de la página web del Ministerio de Agricultura, Pesca y Alimentación relativa a las Costas y el Medio Marino: https://www.miteco.gob.es/es/costas/temas/procedimientos-gestion-dominio-publico-maritimoterrestre/linea-deslinde/default.aspx
} 
de reconocer el aumento progresivo en el importe de las partidas presupuestarias, siguen siendo cantidades insuficientes para las numerosas y complejas actuaciones que se deben llevar a cabo en nuestras costas.

Sobre el balance de la efectividad de la Ley de 1988 el Parlamento Europeo elaboró y publicó en marzo de 2009 el conocido como "informe Auken" ${ }^{22}$. En este documento se hacía una dura crítica a la Ley de Costas y a la irresponsabilidad que habían demostrado las Administraciones Públicas de nuestro país con respecto a la protección del litoral. En un total de 39 considerandos se resalta la inmunidad de los autores de los numerosos daños en las costas españolas y la falta de indemnización a los propietarios de terrenos en dominio público marítimo-terrestre que han sido despojados de sus propiedades.

\section{2.b. La Ley 2/2013 de Protección y Uso Sostenible del Litoral.}

Habiendo transcurrido más de veinte años desde la promulgación de la Ley de Costas las circunstancias tanto del país como de las zonas costeras habían cambiado, por lo que se hizo necesario acometer una reforma de la regulación concerniente al dominio público marítimo-terrestre. El 29 de mayo de 2013 se aprobaba, por fin, la necesaria revisión de la ley. En la Exposición de Motivos nos encontramos con los objetivos que se marca el legislador con la reforma legislativa. En primer lugar, y reiterando el objetivo que se plantean todas las regulaciones del medio costero, se pretende lograr un equilibrio entre el respeto al dominio litoral y el uso del mismo de manera considerada y adecuada a su conservación. A su vez, se trata de ofrecer una mayor seguridad jurídica a todos los agentes que están implicados en la gestión y el uso de las zonas costeras, así como de respetar el complejo reparto competencial que se da sobre el litoral. Por último, se hace hincapié en el propósito de no dilatar los efectos de la regulación contenida en la Ley, aspecto ampliamente criticado de la anterior norma de $1988^{23}$.

Uno de los aspectos más destacados de la reforma legislativa es la redefinición del litoral y de su modo de delimitación. En el preámbulo de la Ley se define el litoral como "franja de terreno en la que se encuentra el mar con la tierra". Para delimitar en concreción esta franja se establecen límites mucho más precisos y técnicos que en las anteriores normas reguladoras, de manera que la aplicación de las mismas sea uniforme en todo el territorio nacional y se dote así a los deslindes de una mayor seguridad jurídica para todos los intervinientes y afectados. Precisamente en relación a los deslindes se señala que aquellos terrenos que pasen a ser parte del dominio público marítimo-terrestre ostentarán a partir de ese momento una concesión gratuita de ocupación y aprovechamiento por un plazo de setenta y cinco años, salvo que renuncien expresamente a ella. Además, se les permite la realización de todas aquellas reparaciones, mejoras y consolidaciones que no impliquen aumento de volumen, altura ni superficie en la construcción original, siempre que constituyan una mejora de la eficiencia energética de la edificación y que, en la medida de lo posible, se utilicen elementos que supongan ahorro en el consumo de agua.

Otra de las novedades que generó más comentarios con la entrada en vigor de la Ley fue

\footnotetext{
22 "Informe sobre el impacto de la urbanización extensiva en España en los derechos individuales de los ciudadanos europeos, el medio ambiente y la aplicación del Derecho Comunitario, con fundamento en determinadas peticiones recibidas" (2008/2248(INI)), publicado por la Comisión de Peticiones del Parlamento Europeo el 20 de febrero de 2009. El informe es conocido con el sobrenombre de "Informe Auken" por el apellido de la eurodiputada danesa Margrete Auken, ponente del mismo.

${ }^{23}$ Extraído de la página web: http://www.notariosyregistradores.com/doctrina/resumenes/2013-reformaley-de-costas.htm
} 
la exclusión de determinados núcleos de población del dominio público marítimoterrestre cuya incorporación al dominio público se produjo por deslindes realizados con anterioridad a 1988 (entre ellos El Palo y Pedregalejo en la provincia de Málaga). Según lo expuesto en el texto de la Ley, estas exclusiones tienen como motivo dar respuesta a las singularidades que presentan estos enclaves, "cuya degradación y características físicas actuales los hacen innecesarios para la protección o utilización del dominio público"24.

Punto muy comentado de la reforma fue también el conceder al Delegado del Gobierno la potestad de decidir suspender de efectos aquellos actos y acuerdos adoptados por las Entidades Locales que fuesen considerados como una posible amenaza a la integridad del dominio público marítimo-terrestre o del área de servidumbre de protección ${ }^{25}$. Esta cláusula se conoce como "cláusula anti-Algarrobico", en referencia al conocido caso del hotel construido en dicho municipio de Almería ${ }^{26}$ contraviniendo las prescripciones de la Ley. Esta medida no ha estado en absoluto exenta de polémica, ya que desde diversos sectores sociales se ha venido considerando que con la misma se invaden las competencias autonómicas en materia de urbanismo y ordenación del territorio litoral. En el mismo sentido, se ha señalado por diversos autores de la doctrina como una vulneración de la autonomía municipal a la que hace referencia el artículo 137 de la Constitución Española, y del sistema jurisdiccional (y no administrativo) de revisión y control de los actos de las Entidades Locales que se establece en los artículos 65, 66 y 67 de la Ley reguladora de las Bases del Régimen Local. Sin embargo, es precisamente en el último de estos preceptos donde el legislador ha encontrado la base ideal para la redacción de esta controvertida cláusula. En él se posibilita la suspensión gubernativa, con necesidad de posterior recurso contencioso, de actos o acuerdos municipales siempre que se considere que atentan gravemente al interés general.

Por último, pero no por ello menos importante, debemos comentar la modificación que hace la nueva Ley de Costas del régimen transitorio establecido por la norma anterior. La Ley de 2013 amplía el régimen concesional de manera generalizada y generosa. Las razones para llevar a cabo este alargamiento de la duración de las concesiones son varias: cumplir con las peticiones del informe $A_{u k e n}{ }^{27}$, evitar la "avalancha" de vencimientos de las concesiones que se produciría de forma masiva en 2018 , y, en último término, corregir la intervención pública que se efectuó con el régimen transitorio de la anterior Ley de Costas, transformando derechos privados legalmente adquiridos en titularidades públicas sin conceder a dichos ciudadanos la indemnización correspondiente. En concreto, las concesiones que se otorguen con posterioridad a la entrada en vigor de la Ley 2/2013 pasan a tener a partir de ese momento el derecho a solicitar que su duración se extienda a los 75 años, en lugar de los 30 establecidos en primer término. Se precisa en la Ley que es posible que algunos títulos concesionales más concretos tengan una prórroga de menor extensión en función del uso que se pretenda dar al suelo ${ }^{28}$. Por su parte, para aquellas concesiones ya existentes antes de la Reforma, se prevé su prórroga por un máximo de 75 años $^{29}$.

A pesar de denominar estas prórrogas como "extraordinarias" en el Preámbulo de la

\footnotetext{
${ }^{24}$ BALZA AGUILERA, J., y otros (2013): "La Reforma de la Ley de Costas”, Actualidad Jurídica Uría Menéndez, 35-2013, pág. 102.

${ }^{25}$ Ver artículo 119 de la Ley 2/2013 de Protección y Uso Sostenible del Litoral.

${ }^{26}$ Ver apartado 3.3.

${ }^{27}$ Ver apartado 2.2.a, pág. 9.

${ }^{28}$ Ver artículo 135 del Reglamento General de Costas.

${ }^{29}$ Ver artículo 2 de la Ley $2 / 2013$.
} 
norma, las mismas pueden ser solicitadas por todos los concesionarios, con la única excepción de las zonas de servicio de los puertos (cuya concesión no puede ser prorrogada bajo ningún concepto) y los terrenos destinados a usos industriales, que disfrutan de un régimen especial de prórrogas. Se puede afirmar, por tanto, que no son en absoluto casos excepcionales ni "extraordinarios", más bien al contrario, se trata de una extensión de la duración de las concesiones generalizada: la Administración está obligada a conceder dichas prórrogas siempre que los titulares de los terrenos afectados las soliciten, puesto que no se requiere en el articulado de la Ley ningún otro requisito.

Finalmente, señalar que el desarrollo reglamentario de la Ley se realizó un año después de la entrada en vigor de la misma. El Reglamento General de Costas (RGC) se aprobó mediante el Real Decreto 876/2014, de 10 de octubre, y en el mismo se desarrolla la normativa reglamentaria referente tanto a la Ley de Costas de 1988 como a la Ley 2/2013. En el RGC nos encontramos con variadas medidas tendentes a la protección, utilización, determinación y policía del dominio público marítimo-terrestre, con especial interés en la ribera marítima, marcándose como objetivos, entre otros, la protección de dicho dominio público y la seguridad jurídica tan necesaria en las acciones que tengan que ver con el mismo.

\subsection{La regulación del litoral por las Comunidades Autónomas.}

Como hemos tratado con anterioridad en este capítulo, la competencia para la protección de las costas se encuentra otorgada a la Administración General del Estado. Sin embargo, tal y como se posibilita legalmente, esta regulación ha sido asumida por las Comunidades Autónomas, quedando a expensas del Estado la regulación básica. A su vez, las Administraciones autonómicas tienen competencias en materia de ordenación del territorio y urbanismo. Por tanto, nos encontramos con una dicotomía "titularidad-planificación" en la que, si bien el dominio público marítimo-terrestre es de titularidad estatal, la planificación del mismo corresponde de manera generalizada a las Comunidades Autónomas.

Se trata de una distribución competencial compleja, en la que se solapan competencias compartidas por ambos niveles administrativos (protección del medio ambiente) y exclusivas de la administración autonómica (ordenación del territorio y urbanismo), esquema que dificulta evidentemente la gestión y protección de las zonas costeras. Es imposible separar la gestión urbanística del litoral de la protección medioambiental de la que se debe dotar al mismo.

En base a este marco competencial, casi ninguna Comunidad Autónoma ha querido quedar al margen de la ordenación del litoral, y han dado soluciones autonómicas y diferenciadas a estas zonas en atención a la gran complejidad de los intereses públicos y también privados que confluyen sobre ellas. En los siguientes capítulos desarrollaremos los instrumentos, estrategias y planes concretos que han sido puestos en marcha desde las Comunidades Autónomas de Andalucía y del Principado de Asturias, de manera que podamos observar las diferencias y similitudes que se presentan en ambas gestiones. 


\section{El litoral andaluz.}

\subsection{Legislación de la Comunidad Autónoma de Andalucía en materia de costas. Los instrumentos de la ordenación del territorio y su relación con el litoral.}

Los principales ejes de la regulación actual del litoral en la Comunidad Autónoma andaluza se encuentran recogidos en la Ley 7/2002, de 17 de diciembre, de Ordenación Urbanística de Andalucía ${ }^{30}$, y es precisamente sobre ellos que deben articularse los planes urbanísticos que se lleven a cabo en los municipios costeros de las provincias andaluzas. En la propia Exposición de Motivos de la Ley de Ordenación se hacen referencias expresas al litoral y al uso sostenible que debe hacerse de él, principios que deben inspirar toda la regulación territorial y urbanística de la Comunidad Autónoma: "El uso racional y sostenible de los recursos naturales, la protección del medio ambiente y del paisaje y específicamente la protección y adecuada utilización del litoral constituyen fines específicos, también, de esta Ley. Tales principios son instrumentados a lo largo de su texto, desde el objeto y contenidos básicos de los planes urbanísticos, a la clasificación de los suelos, o a la tipificación de las infracciones y sanciones."

Haciendo un pequeño paréntesis temporal, es necesario mencionar el intento realizado por la Junta de Andalucía durante la década de los noventa de llevar a cabo una ordenación sostenible de su litoral. Las Directrices Regionales del Litoral de Andalucía $^{31}$, aprobadas en 1990, y el Programa de Planeamiento Litoral (1985-1992), constituían un sistema de planificación y gestión del espacio costero orientado a la ordenada inserción de las actividades sobre el territorio. Según lo establecido en el artículo 1.1 de las Directrices, la finalidad de las mismas era “...servir de marco de referencia para el desarrollo de las políticas sectoriales y el planeamiento urbanístico que sobre dicho ámbito se efectúe, los cuales deberán asegurar la compatibilización del uso y aprovechamiento de las potencialidades del litoral con la preservación y renovación de sus recursos." De manera muy coherente se expresaba en el siguiente apartado del precepto el carácter vinculante que poseía el texto normativo para con las Administraciones Públicas andaluzas: "Las disposiciones contenidas en las Directrices tienen carácter vinculante para la actuación pública en cuanto a los objetivos y resultados que deben lograrse en el ámbito litoral, dejando los medios y forma concretos para conseguirlos a los distintos organismos administrativos, que deberán asegurar la coordinación de sus actuaciones para la más adecuada gestión del litoral y sus recursos. " Por su parte, el Programa de Planeamiento Litoral consistía en una serie de iniciativas de carácter supramunicipal que aspiraban a definir un marco de coherencia para la ordenación física de las zonas costeras a través de sus correspondientes instrumentos de planeamiento urbanístico.

Ambos documentos, por distintas razones, no llegaron a buen puerto. En el Decreto de aprobación de las Directrices se indicaba lo siguiente: "Artículo único. Se aprueban las Directrices Regionales del Litoral de Andalucía, con arreglo al texto incorporado al presente Decreto." Sin embargo, no fue así, el texto de las Directrices nunca llegó a publicarse. En consecuencia, estas normas no llegaron a incorporarse nunca de manera

\footnotetext{
${ }^{30}$ Ver artículos 3.2.g), 9.A.f), 10.1.A.i) y 17.7 de la Ley de Ordenación Urbanística de Andalucía.

${ }^{31}$ En 1985 se inician los trámites para su aprobación mediante el Decreto 76/1985, de 3 de abril, por el que el Consejo de Gobierno de la Junta de Andalucía autoriza la formulación de las directrices regionales del litoral de Andalucía. Su aprobación definitiva se producirá por el Decreto 118/1990, de 17 de abril.
} 
efectiva a la gestión y el desarrollo de las políticas urbanísticas y de ordenación del territorio que se llevaron a cabo en Andalucía en años posteriores.

Al respecto de la inaplicación de las Directrices ha sido precisamente una institución externa a la Junta de Andalucía, el Defensor del Pueblo Andaluz, la única en elaborar un informe $^{32}$ acerca de los efectos y cumplimiento de esta estrategia fallida de gestión del litoral. En este texto el Defensor llegó a manifestar, literalmente, que le resultaba "inexplicable" y "controvertida" la no publicación del texto de las Directrices. Tras llevar a cabo una serie de cuestionarios a las Administraciones Públicas implicadas en la aplicación de las Directrices (Ayuntamientos y Junta de Andalucía), elaboró una valoración crítica general de la efectividad de las disposiciones normativas así como una serie de recomendaciones y sugerencias en base a los resultados obtenidos ${ }^{33}$.

Retomando los instrumentos de planeamiento que han tenido verdadera relevancia en la ordenación territorial del litoral andaluz, hemos de comenzar por el documento básico, el Plan de Ordenación del Territorio de Andalucía ${ }^{34}$, conocido como POTA. Es un instrumento de planificación y ordenación integral del territorio andaluz en el que se indican los elementos esenciales de su estructura, respetando los cuales deben elaborarse los planes de ámbito subregional y todas aquellas actuaciones que puedan influir en la ordenación del territorio, tales como obras públicas o actuaciones privadas de cualquier índole.

Otro instrumento legal a tener en cuenta en el planeamiento urbanístico litoral en Andalucía es el más reciente Decreto-Ley 5/2012, de 27 de noviembre, de Medidas Urgentes en Materia Urbanística y Protección del Litoral de Andalucía. Esta norma fue elaborada, principalmente, con motivo de la escasa respuesta de los municipios costeros andaluces a las determinaciones del POTA. Entre las iniciativas incluidas en el DecretoLey de 2012 se encuentra el establecimiento de plazos concretos para que los municipios realicen las adaptaciones, o la posibilidad de que la Consejería competente en materia de urbanismo se subrogue en la posición de los Ayuntamientos y proceda a revisar el planeamiento si éstos no cumplen su obligación dentro de plazo. En el caso concreto de los municipios costeros, se prevé la suspensión cautelar de los procedimientos de aprobación de Planes de Sectorización o de Planes Parciales en suelo urbanizable en aquellos casos en los que se vean afectados terrenos situados a una distancia inferior a 500 metros desde el límite interior de la ribera del mar.

\footnotetext{
32 "La ordenación y protección del espacio litoral andaluz: Estudio sobre la posición de las Administraciones Públicas ante el Decreto 118/1990, por el que se aprueban las Directrices Regionales del Litoral de Andalucía." Realizado por el Defensor del Pueblo Andaluz en octubre de 1995.

33 ACOSTA BONO, G. (1999): “Ordenación del litoral y política territorial en Andalucía”, Actas de las Jornadas sobre el litoral de Almería: caracterización, ordenación y gestión de un espacio geográfico, celebradas en Almería, 20 a 24 de mayo de 1997, págs. 111 - 125.

${ }^{34}$ El Plan de Ordenación del Territorio de Andalucía se aprobó por medio del Decreto 206/2006, de 28 de noviembre, y fue publicado en el Boletín Oficial de la Junta de Andalucía de 29 de diciembre de 2006. Su elaboración y aprobación se realizó según lo establecido en la Ley 1/1994 de Ordenación del Territorio de la Comunidad Autónoma de Andalucía, el Decreto 83/1995, de 28 de marzo, por el que se acordó su formulación y el Decreto 103/1999, de 4 de mayo, por el que se aprobaron las Bases y Estrategias del Plan de Ordenación del Territorio de Andalucía, documento de carácter preparatorio, que estableció el diagnóstico de las oportunidades y problemas regionales, el Modelo Territorial de Andalucía y las principales estrategias sobre las estructuras y sistemas regionales.
} 


\subsection{El Plan de Protección del Corredor Litoral de Andalucía.}

Este documento fue el más importante de los instrumentos de planeamiento elaborados en Andalucía que ordenaban y regulaban la planificación y protección del territorio litoral. Fue precisamente el Decreto-Ley 5/2012 anteriormente citado el que incorporó el PPCLA a la planificación territorial andaluza, modificando la Ley 1/1994 de Ordenación del Territorio de la Comunidad Autónoma de Andalucía para añadir un nuevo Título dedicado por completo al PPCLA ${ }^{35}$.

Se trata de un instrumento de reciente aprobación ${ }^{36}$ que se diseñó como complemento al POTA y a los planes de ordenación del territorio de ámbito subregional. Desde el gobierno autonómico se quiso dar solución a los problemas que presentan estas zonas, densamente pobladas y altamente urbanizadas en su mayoría, intentando a su vez elevar el nivel de protección y conservación del litoral andaluz. Con las medidas establecidas en el PPCLA se perseguía de manera inequívoca la preservación de todos aquellos terrenos aún sin urbanizar en la zona costera, de manera que se evitase la consolidación de núcleos urbanos y la destrucción del entorno natural.

En líneas generales, se trataba de un Plan que, a pesar de haber sido ampliamente criticado por los municipios costeros, no ampliaba en demasía las determinaciones básicas de protección marcadas por la Ley de Costas. Ejemplo de ello es que la franja litoral sobre la que extiende su ámbito es de 500 metros desde el límite interior de la ribera del mar (salvo pequeñas excepciones en las que esta se amplía para incluir suelos protegidos por la planificación territorial o ámbitos de características fisiográficas homogéneas), siendo esta la extensión mínima que fija la Ley de Costas para la zona de influencia.

Hablamos del Plan en pasado ya que, a pesar de sus buenos propósitos, en septiembre de 2017 el mismo era anulado por el TSJA. Con fecha 23 de abril de 2018 se dictaba resolución desde la Secretaría General Técnica de la Consejería de Medio Ambiente y Ordenación del Territorio de la Junta de Andalucía por la que se disponía el cumplimiento del fallo de la sentencia del TSJA de fecha 7 de septiembre de $2017^{37}$, en el cual se dejaba sin efecto el PPCLA. La anulación ${ }^{38}$ del Plan tiene su origen en el recurso contencioso que varios Ayuntamientos afectados interpusieron contra el documento tras su aprobación, al considerar que el Gobierno de la Junta no estaba facultado para tramitar dicho instrumento urbanístico puesto que se encontraba "en funciones" cuando procedió a aprobarlo en Consejo de Gobierno. El TSJA le dio la

\footnotetext{
${ }^{35}$ Ver artículo 1.3 del Decreto-Ley 5/2012 de Medidas Urgentes y artículos 42, 43 y 44 de la Ley 1/1994 de Ordenación del Territorio de la Comunidad Autónoma de Andalucía.

${ }^{36}$ El Plan de Protección del Corredor del Litoral fue aprobado por el Consejo de Gobierno de la Junta de Andalucía mediante Decreto 141/2015, de 26 de Mayo, y se publicó en el Boletín Oficial de la Junta de Andalucía el 20 de julio de 2015. La elaboración del PPCLA no fue todo lo rápida que debería haber sido en base a las necesidades urgentes que debía atender. De hecho, su aprobación se produjo sólo dos días antes de que venciera el plazo establecido al efecto en el Decreto-Ley 15/2014, de 25 de noviembre, por el que se modifica el Decreto-Ley 5/2012 de Medidas Urgentes. En la norma original se había establecido un plazo de dos años y seis meses desde su entrada en vigor para que se produjera la aprobación del Plan de Protección. En el Decreto-Ley de 2014 se vuelve a conceder un nuevo plazo de dos años y seis meses para llevar a cabo la elaboración del instrumento legal.

${ }^{37}$ Ver Sentencia de la Sección Segunda de la Sala de lo Contencioso-Administrativo del TSJA, con sede en Sevilla, número 7921/2017, de 7 de septiembre.

${ }^{38}$ Al respecto de la anulación del PPCLA: RANDO BURGOS, E., (2018): "La anulación del Plan de Protección del Corredor Litoral de Andalucía por el Tribunal Superior de Justicia de Andalucía: ¿nuevas dificultades en la planificación territorial de Andalucía?", Revista de Estudios de la Administración Local y Autonómica: Nueva Época, ISSN-e 1989-8975, N. 10, 2018, págs. 109 - 131.
} 
razón a estos Consistorios en su sentencia, entendiendo que era factible y razonable esperar a la constitución del nuevo Gobierno autonómico para proceder a su aprobación al no tratarse de un asunto de carácter urgente. La Junta de Andalucía ha recurrido dicho fallo en casación ante el Tribunal Supremo, pero este ha inadmitido a trámite el recurso $^{39}$ al considerar que la controversia se ceñía al ámbito autonómico, siendo la máxima autoridad judicial en el mismo el TSJA.

Volviendo al contenido del Plan anulado, hemos de señalar que para conseguir todos los objetivos propuestos por el mismo se llevaban a cabo básicamente dos tipos de acciones en el texto del Plan. Por un lado, se establecía de manera concreta la extensión de la denominada Zona de Influencia del Litoral y se delimitaban las zonas específicas de protección que debían ser preservadas del desarrollo urbanístico. Por otro, se establecían las medidas y previsiones necesarias para adaptar los planeamientos de ámbito subregional a lo dispuesto en el PPCLA.

En relación al ámbito de aplicación del Plan hemos de señalar que se incluían al menos los primeros 500 metros de la Zona de Influencia del Litoral así como aquellas otras zonas que fuesen necesarias según la Administración autonómica para conseguir los objetivos de protección y accesibilidad del litoral. Todas las medidas establecidas en el Plan de Protección seguían uniformemente los criterios establecidos en el POTA, a saber, la consideración unitaria de la sostenibilidad económica y ecológica, la protección integral de los sistemas litorales evitando la formación de continuos urbanos en el frente costero, la protección del paisaje, la preservación del patrimonio natural y la protección de la costa frente a los riesgos evidentes de erosión.

Teniendo en cuenta todas estas determinaciones y con el fin de conseguir los objetivos propuestos, se establecían en el PPCLA las siguientes categorías de protección para las diferentes áreas que componen el litoral andaluz ${ }^{40}$ :

- Zonas Litorales de Protección Ambiental:

En esta categoría se incluían todos aquellos suelos delimitados como Espacios Naturales Protegidos, Red Natura 2000, montes de dominio público, vías pecuarias y dominio público marítimo-terrestre e hidráulico, que conforme a la legislación e instrumentos de planificación correspondiente se encontrasen incluidas en el área litoral. Todas estas áreas ostentaban un régimen especial de uso del suelo de acuerdo con lo establecido en el Plan de Protección y demás normativa urbanística que les sea aplicable.

\section{- Zonas Litorales de Protección Territorial I:}

Quedaban incluidos en esta categoría aquellos suelos con valores naturales o paisajísticos de interés que fuesen colindantes con el dominio público marítimoterrestre o con las Zonas Litorales de Protección Ambiental, así como todos los suelos que conectasen la costa con los espacios naturales protegidos del interior de Andalucía. Eran clasificadas como Suelo No Urbanizable de Especial Protección, de manera que no era posible realizar ningún tipo de edificación o construcción en ellos, y se establecían al efecto medidas de conservación de los recursos naturales existentes en las mismas.

\footnotetext{
${ }^{39}$ Ver Providencia de la Sección $1^{\text {a }}$ de la Sala de lo Contencioso-Administrativo del Tribunal Supremo de fecha 26 de febrero de 2018.

${ }^{40}$ Extraído de la página web de la Consejería de Medio Ambiente y Ordenación del Territorio de la Junta de Andalucía relativa al Plan de Protección del Corredor Litoral de Andalucía.
} 


\section{- Zonas Litorales de Protección Territorial II:}

Se incluían en esta categoría aquellos suelos con valores naturales o paisajísticos dignos de protección, así como los suelos de transición entre espacios urbanizados, los suelos facilitadores de la conexión costa-interior, los suelos libres de edificación que cumplen funciones territoriales específicas, la costa y las zonas con valores naturales, y suelos que estuviesen en riesgo de erosión, desprendimientos, corrimientos, inundaciones u otros peligros de carácter natural. Eran igualmente clasificadas como Suelo No Urbanizable de Especial Protección, o bien como espacios libres, y se establecían para ellos medidas de conservación de los recursos paisajísticos, agrícolas y forestales.

\subsection{Un ejemplo de la dicotomía desarrollo urbanístico-protección del litoral: el caso del hotel de El Algarrobico.}

El hotel comenzado a construir en 2003 en el municipio almeriense de Carboneras es uno de los casos más graves y más conocidos de ilegalidad urbanística en el litoral andaluz. Un claro ejemplo de la complejidad que implica compaginar el desarrollo turístico, y por ende urbanístico, de un municipio con la protección del medio ambiente $y$ de los recursos naturales que poseemos en nuestras $\operatorname{costas}^{41}$.

La playa de El Algarrobico fue clasificada en 1987 por el Ayuntamiento de Carboneras como urbanizable en sus Normas Subsidiarias y, curiosamente, ese mismo año se creaba el Parque Natural de Cabo de Gata-Níjar sin incluir en su ámbito de delimitación dicho paraje costero. Sin embargo, un año después entraba en vigor la Ley de Costas, que establecía la ya conocida servidumbre de protección en zonas litorales en un área de 100 metros desde la ribera del mar. A pesar de ello, el Ayuntamiento de Carboneras aprobaba ese año un Plan Parcial que urbanizaba esta zona, y obviaba adaptar su planeamiento a dicha servidumbre.

Seis años más tarde, en 1994, la Junta de Andalucía aprueba el Plan de Ordenación de los Recursos Naturales (PORN) y el Plan Rector de Uso y Gestión (PRUG) del Parque Natural de Cabo de Gata-Nijar ${ }^{42}$. En dichos instrumentos el terreno donde posteriormente se alojaría el hotel de El Algarrobico sí aparece incluido en el ámbito del Parque Natural, y es clasificado en el texto como no urbanizable. Sin embargo, en 1997 se publican tres mapas cartográficos en base al PORN y al PRUG en los que esa clasificación se modifica. El suelo donde se ubica el Algarrobico es ahora, según estos nuevos planos, urbanizable.

La licencia de obras fue concedida en el año 2003, comenzando con ello la construcción $\mathrm{y}$, simultáneamente, las protestas desde diversos sectores sociales. El hotel se encontraba situado (y se encuentra, ya que a día de hoy aún no se ha procedido a su demolición) a menos de 50 metros de la línea de deslinde de la ribera del mar. De hecho, una piscina y diversas construcciones accesorias del hotel que se realizaron a pie

\footnotetext{
41 Al respecto de la sostenibilidad turística: ZAMORA ROSELLÓ, M.R., (2017): "La sostenibilidad turística a través de los instrumentos andaluces de planificación”, Revista Andaluza de Administración Pública, ISSN 1130-376X, №. 98, 2017, págs. 395 - 426.

42 Decreto 418/1994, de 25 de octubre, por el que se aprobaron el Plan de Ordenación de los Recursos Naturales, con una vigencia de ocho años, y el Plan Rector de Uso y Gestión del Parque Natural Cabo de Gata-Níjar, con una vigencia de cuatro años, que fue prorrogada por el Decreto 73/2000, de 21 de febrero, hasta la entrada en vigor de un nuevo Plan. Asimismo, el Decreto 418/1994 modificó los límites del Parque Natural Cabo de Gata-Níjar, ampliando su superficie.
} 
de playa se separaban apenas catorce metros de dicha línea ${ }^{43}$.

En el año 2005 se realiza el deslinde de la servidumbre de protección ${ }^{44}$ y desde el Ministerio de Medio Ambiente se inician los trámites para la expropiación de los terrenos del dominio público marítimo-terrestre del paraje de El Algarrobico. Las obras del hotel, que estaban ya a punto de finalizar (construido prácticamente el $95 \%$ del complejo), son paralizadas un año más tarde por el Juzgado de lo ContenciosoAdministrativo (JCA) $\mathrm{n}^{\mathrm{o}} 2$ de Almería a respuesta de una denuncia interpuesta por la asociación ecologista "Salvemos Mojácar". Ya en 2007 el Consejo de Ministros declara los terrenos en conflicto de utilidad pública, pasando estos a formar parte del dominio público marítimo-terrestre. A partir de este año comienza una larga batalla en los tribunales para conseguir la demolición del hotel y la preservación del paraje natural de El Algarrobico.

En 2008 se confirma mediante Sentencia de la Audiencia Nacional ${ }^{45}$ la legalidad de la Orden Ministerial de 2005 en la que se aprobaba el deslinde. Se publica en estas mismas fechas un nuevo PORN del Parque Natural de Cabo de Gata-Níjar ${ }^{46}$ en el cual el terreno correspondiente a El Algarrobico es clasificado como "área degradada", a diferencia de su clasificación en el PORN anterior como "zona de especial protección no urbanizable". En respuesta a este cambio de clasificación la asociación ecologista Greenpeace España solicita al Tribunal Superior de Justicia de Andalucía (TSJA) que se adopten medidas cautelares y se anule este nuevo PORN en lo referente al área de El Algarrobico, consiguiendo que el Tribunal dictamine la suspensión cautelar ${ }^{47}$ del texto normativo. A su vez, el Ayuntamiento de Carboneras recibía sentencia del JCA no 2 de Almería en la que se le obligaba a revisar de oficio la licencia de obras concedida, puesto que la misma no era conforme a Derecho.

A esta serie de impedimentos para la finalización de la construcción del hotel se suma en 2009 la reapertura, por parte de la Fiscalía Provincial de Almería, de la investigación sobre presuntos indicios de prevaricación y delitos contra la ordenación del territorio por parte de las Administraciones Públicas intervinientes en el caso ${ }^{48}$. Como con todos los hechos ocurridos durante la cronología de este asunto, a esta noticia se sumaba otra en sentido totalmente contrario. También en 2009 el Ministerio de Medio Ambiente, Rural y Marino arrojaba un jarro de agua fría sobre el caso dictando una resolución por la cual abandonaba la expropiación de los terrenos del hotel.

Pero no todo serían malas noticias para la protección del litoral almeriense. En 2011 el

\footnotetext{
43 Datos obtenidos en la página web de Greenpeace España: https://es.greenpeace.org/es/trabajamosen/oceanos/costas/algarrobico-simbolo-de-la-destruccion-de-la-costa/

${ }^{44}$ Orden Ministerial de 8 noviembre de 2005 por la que se aprueba el deslinde de los bienes de dominio público marítimo-terrestre del tramo de costa de 5.791 metros de longitud comprendido desde el final de playa de El Lacón hasta el límite con el término municipal de Carboneras.

45 Ver Sentencia de la Sección Primera de la Sala de lo Contencioso Administrativo de la Audiencia Nacional de fecha 23 de enero de 2008.

46 Decreto 37/2008, de 5 de febrero, por el que se aprueba el Plan de Ordenación de los Recursos Naturales y el Plan Rector de Uso y Gestión del Parque Natural Cabo de Gata-Níjar y se precisan los límites del citado Parque Natural.

${ }^{47}$ Ver Autos de la Sección Primera de la Sala de lo Contencioso Administrativo del TSJA con sede en Granada de fecha 25 de noviembre de 2008 y 17 de marzo de 2009. Véase también la Sentencia firme de 11 de junio de 2012 de la Sección Primera de la Sala de lo Contencioso Administrativo del TSJA con sede en Granada por la que se anula el PORN de 2008 y se restablece en el Algarrobico el nivel de protección que tenía en el PORN de 1994, como espacio protegido no urbanizable.

48 Noticia publicada en el diario El Mundo el 28 de febrero de 2009: "Reapertura del caso por prevaricación y contra la ordenación del territorio" (Europa Press Almería).
} 
Tribunal Supremo confirmaba ${ }^{49}$ la decisión del TSJA de suspender la aplicación del PORN de 2008 y se reestablecía en su lugar la vigencia del PORN de 1994, con la consiguiente calificación (mucho más apropiada según la opinión de quien suscribe) de este área como "zona de especial protección no urbanizable". El procedimiento sobre la legalidad del deslinde de la zona de servidumbre de protección también llegaba a su fin en el año 2012: se confirmaba su legalidad mediante sentencia del Tribunal Supremo ${ }^{50}$, a la vez que el TSJA determinaba que el suelo sobre el que se asienta el hotel es una zona perteneciente al Parque Natural de Cabo de Gata-Níjar, y por tanto, suelo calificado como no urbanizable ${ }^{51}$.

Parecía que todos los pronunciamientos judiciales se decantaban por la ilegalidad de lo construido y el restablecimiento de los terrenos a su estado original. Sin embargo, en 2014 se produce lo inesperado: en dos nuevas sentencias ${ }^{52}$ el TSJA se pronuncia a favor de la legalidad de la licencia y de la calificación del suelo como urbanizable. En el primero de los pronunciamientos basa su decisión en la discordancia existente entre el texto del PORN de 1994 y su propia planimetría adjunta. Según la opinión del TSJA, prevalece siempre lo determinado en el texto de la norma, de ahí que decida mantener la calificación de los terrenos del hotel como urbanizables, culpando en la sentencia a las autoridades autonómicas, que no procedieron en su momento a revisar las normas urbanísticas a pesar de la clara contradicción de éstas con la Ley de Costas. La segunda sentencia, relativa a la legalidad de la licencia de obras, centra su fundamentación, de nuevo, en la inactividad de las Administraciones Públicas competentes. Desde la Junta de Andalucía se había dado el visto bueno al planeamiento urbanístico del municipio. No habiéndose impugnado ni revisado ese instrumento, la licencia de obras concedida en base al mismo era completamente legal. De hecho, el Tribunal señala que con la pretensión de anulación de la licencia se está pidiendo de manera velada la declaración de ilegalidad de la normativa urbanística en la que está basada ${ }^{53}$.

Desde la Junta de Andalucía se afirmó que ambas resoluciones serían recurridas en casación ante el Tribunal Supremo, pero finalmente sólo sucedió en el primer caso. El Alto Tribunal emitió su decisión el 10 de julio de 2016 ${ }^{54}$ : el hotel está construido en suelo no urbanizable. Contra la segunda sentencia se promovieron incidentes de nulidad tanto por parte de asociaciones ecologistas como por la propia Junta de Andalucía, pero fueron desestimados. Habiendo devenido firme la sentencia de julio de 2014, la asociación ecologista Salvemos Mojácar presentó, en mayo de 2016, recurso ante el Tribunal Europeo de Derechos Humanos, admitido a trámite en julio del mismo año ${ }^{55}$.

El día 19 del pasado mes de abril la Sección $5^{\text {a }}$ de la Sala de lo ContenciosoAdministrativo del Tribunal Supremo desestimó el recurso de casación interpuesto por el Ayuntamiento de Carboneras contra la sentencia del TSJA de fecha 18 de julio de

\footnotetext{
${ }^{49}$ Ver Sentencia del Tribunal Supremo, de fecha 30 de septiembre de 2011.

${ }^{50}$ Ver Sentencia del Tribunal Supremo de fecha 18 de julio de 2012.

${ }^{51}$ Ver Sentencia de la Sección Primera de la Sala de lo Contencioso Administrativo del TSJA con sede en Granada, número 1951/2012, de 11 de junio.

${ }^{52}$ Ver sentencias de la Sección Tercera de la Sala de lo Contencioso-Administrativo del TSJA con sede en Granada de 21 de marzo y 29 de julio de 2014. Nótese que se trata de una Sección de la Sala diferente a la que venía enjuiciando hasta el momento los asuntos relacionados con El Algarrobico.

53 CUESTA REVILLA, J. (2013): "A vueltas con El Algarrobico: la historia interminable de un despropósito medioambiental", Revista Vasca de Administración Pública, № 99-100, págs. 1041 - 1052.

${ }^{54}$ Ver sentencia número 272/2016, de la Sección Quinta de la Sala de lo Contencioso-Administrativo del Tribunal Supremo, de 10 de febrero.

${ }^{55}$ Noticia publicada en la página web de Europa Press el 15 de julio de 2016: "Estrasburgo admite la demanda contra el fallo que declaró legal la licencia del Algarrobico".
} 
2016. En el pronunciamiento de instancia se revocaba el PGOU de dicho municipio en lo referente a los sectores S-T1 Algarrobico y S-T2 El Canillar, obligando a que los mismos figurasen en el planeamiento urbanístico local como suelo no urbanizable. El Alto Tribunal expone como argumento en su sentencia que el Ayuntamiento de Carboneras no adaptó su PGOU al PORN del año 2008, documento en el que dichos sectores aparecían clasificados como protegidos y, por tanto, no urbanizables. Adaptación a la que, a mayor abundamiento, les obligaba también el Decreto 26/2009, de 3 de febrero, por el que fue aprobado el Plan de Ordenación Territorial del Levante Almeriense. Recuerda además el texto de la sentencia la prevalencia del PORN sobre el planeamiento municipal, argumento que el Ayuntamiento de Carboneras había sostenido en sentido contrario en anteriores litigios sobre el mismo asunto.

En mayo de este año Greenpeace presentó demanda ante el TSJA contra el Ayuntamiento de Carboneras para que éste sea obligado a anular la licencia de obras y a calificar como suelo no urbanizable el paraje de El Algarrobico, de acuerdo con lo indicado por el Tribunal Supremo en su sentencia de fecha 19 de abril. En el mismo mes de septiembre se ha sabido que, en contestación a esta demanda, el Consistorio almeriense ha comunicado al TSJA que ya ha procedido a dar cumplimiento a la sentencia del Tribunal Supremo, modificando la calificación de los terrenos en conflicto de urbanizables a protegidos. Sin embargo, en relación con la licencia de obras alegan, de nuevo, que no es posible declarar la misma como nula, puesto que fue concedida de manera completamente legal.

\section{El litoral asturiano.}

\subsection{Legislación de la Comunidad Autónoma del Principado de Asturias en materia de costas. Los instrumentos de la ordenación del territorio y su relación con el litoral.}

En base a la asignación competencial marcada por la Constitución, los distintos gobiernos del Principado han aprobado una gran diversidad de normas relacionadas de una u otra manera con la gestión y la protección del litoral. De esa extensa relación normativa debemos comenzar por el Texto Refundido de las Disposiciones Legales vigentes en materia de Ordenación del Territorio y Urbanismo ${ }^{56}$ (TROTU), promulgado en 2004, en el que parte de la atomizada legislación vigente quedaba subsumida en el citado Texto Refundido para su mejor y más fácil aplicación.

Dentro de la numerosa regulación incluida en el TROTU son de especial interés para la ordenación de las zonas costeras los artículos 133, 134 y 135, en los cuales se establece el ámbito que ocupa la franja de la servidumbre de protección (mínimo 500 metros desde la ribera del mar, ampliables en aquellos casos en los que las características de la zona concreta así lo requieran) y, además, se delimita una "zona de protección específica" que se extiende 100 metros desde el final de la franja protegida, y en la cual

\footnotetext{
${ }^{56}$ Aprobado por Decreto Legislativo 1/2004, de 22 de abril, este Texto Refundido ya aparecía señalado en la Ley del Principado de Asturias 3/2002, de Régimen del Suelo y Ordenación Urbanística, la cual, en su Disposición final quinta, autorizaba al Gobierno del Principado para la elaboración y aprobación, en el plazo de un año, de un texto refundido que recogiera las disposiciones con rango de ley vigentes en el Principado. Este plazo fue ampliado en la Ley 6/2003 de Medidas Presupuestarias, Administrativas y Fiscales, la cual otorgaba, además, facultades de regularización, aclaración y armonización de los textos legales que hubieran de refundirse.
} 
los usos y aprovechamientos, a excepción de cultivos y plantaciones, estarán sometidos a autorización administrativa.

En cuanto a los instrumentos de planificación propiamente dichos, hemos de destacar necesariamente tres: de ámbito general, las Directrices Regionales de Ordenación del Territorio (DROT), y en cuestión de ordenación del litoral, las Directrices Subregionales de Ordenación del Territorio para la Franja Costera (DSOTFC) y el Plan Territorial Especial de Ordenación del Litoral Asturiano (POLA).

En relación al primero de ellos, las Directrices Regionales de Ordenación del Territorio, es importante destacar que son consideradas como el primer instrumento de planeamiento general de una Comunidad Autónoma española. Fueron aprobadas en 1991 por medio del Decreto 11/1991, de 24 de enero, cumpliendo con el marco legal diseñado al efecto en la Ley 6/1990, de 20 de diciembre, sobre Edificación y Usos en el Medio Rural vigente en ese momento. En el texto de las DROT nos encontramos con una serie de normas que afectan directamente al litoral, como por ejemplo las Directrices 4.3 y 4.4, relativas a transporte y puertos, o la Directriz 9.8, que recomienda la elaboración de unas Subdirectrices especiales para la ordenación de la franja costera del Principado. Esta pronta ordenación del territorio ha influido de manera gratamente positiva en la protección del suelo, consiguiendo, en el caso de la franja costera, que el deterioro sufrido en otros puntos del país no se haya producido en Asturias.

A pesar de los efectos innegablemente positivos de las DROT de 1991, el transcurrir del tiempo hizo evidentes sus faltas y defectos, así como su necesidad de renovación de acuerdo con los problemas actuales del territorio del Principado de Asturias. Es por ello que el Consejo de Gobierno del Principado de Asturias acordó ${ }^{57}$ el 8 de julio de 2004, en el ejercicio de su competencia exclusiva sobre esta materia, iniciar el procedimiento de revisión de las DROT y, paralelamente, la redacción de las Directrices Subregionales del Área Central (DSOTAC). En marzo de 2006 se publicó un avance de las nuevas Directrices, pero sin embargo no es hasta el mes de julio de 2016 (ni más ni menos que doce años después de la aprobación del inicio del procedimiento de revisión) cuando se publica en el Boletín Oficial del Principado de Asturias ${ }^{58}$ el "Documento de Avance de la Revisión de las Directrices Regionales de Ordenación del Territorio de Asturias y Documento Inicial Estratégico" para su información pública por el plazo de dos meses.

Centrándonos ya en el ámbito exclusivamente litoral, podemos afirmar que las Directrices Subregionales de Ordenación del Territorio para la Franja Costera, constituyen el primer documento elaborado en el Principado de Asturias completamente enfocado a la ordenación del territorio litoral. Las DSOTFC, aprobadas mediante Decreto 107/1993, de 16 de diciembre, son elaboradas en cumplimiento del mandato establecido en sus antecesoras, las DROT, concretamente en su Directriz 9.8, tal y como ya hemos señalado en párrafos anteriores de este capítulo, que justificaba la necesidad de su redacción de la siguiente manera: "La especial conveniencia de redactar estas Directrices Subregionales se produce en base al anterior reconocimiento de la franja costera como zona de gran sensibilidad ante las actuaciones con impacto territorial, que obliga a la convergencia en las actuaciones preventivas desde las Administraciones central, autonómica y local."

\footnotetext{
${ }^{57}$ En virtud de lo establecido en los artículos 95 y 96.1 del Decreto 278/2007, de 4 de diciembre, por el que se aprueba el Reglamento de Ordenación del Territorio y Urbanismo de Asturias (ROTU), relativos a la tramitación de instrumentos de planificación territorial.

${ }^{58}$ De conformidad con lo dispuesto en los artículos 46 y siguientes del TROTU, relativos a la formación y aprobación de las Directrices de Ordenación Territorial.
} 
El ámbito territorial de aplicación de las DSOTFC incluye todos los municipios costeros asturianos y sus correspondientes términos municipales, puesto que los problemas que puedan surgir en el litoral muy posiblemente afectarán al resto del área de extensión del municipio. Tal y como observamos al reseñar la novedosa franja de protección determinada en el texto del TROTU ${ }^{59}$, aquí nos encontramos de nuevo ante una extensión del ámbito protegido por la regulación asturiana en materia de costas frente a lo marcado por la legislación básica estatal. Así, en el apartado 3.3.3 del documento que contiene las Directrices se hace la siguiente precisión" ${ }^{60}$ : "La franja litoral sobre la que incide directamente la Ley y Reglamento de Costas es de una extensión mínima comparada con el territorio costero en donde se detectan los problemas que llevan a redactar las presentes Directrices con los objetivos anteriormente enunciados".

En el artículo 4 del Decreto 107/1993 por el que aprobaban las DSOTFC se imponía a la Consejería competente para la ordenación del territorio el deber de redactar, en el plazo de dos años desde la fecha de promulgación del Decreto, un Plan Especial de Protección de Costas que desarrollara los contenidos recogidos en las Directrices Subregionales. Siguiendo con la rapidez legislativa que le caracteriza, el gobierno asturiano aprobó doce años después, concretamente el 23 de mayo de 2005, el texto del Plan Territorial Especial de Ordenación del Litoral Asturiano.

\subsection{El Plan Territorial Especial de Ordenación del Litoral de Asturias.}

Con la aprobación del POLA en 2005 comienza una nueva perspectiva en la actuación preservativa y potenciadora del litoral asturiano por parte del gobierno de la Comunidad Autónoma. De inicio, las directrices marcadas en el texto del Plan hacen que el Principado de Asturias disponga de la mayor franja costera protegida de todo el litoral español (aproximadamente unos $300 \mathrm{~km}$ ). Otro rasgo diferenciador del texto legal es su organización, más práctica en nuestra opinión a la de otros planes de ordenación litoral existentes $^{61}$. El documento se compone de seis tomos: en el primero de ellos se desarrolla la Memoria y la Normativa del Plan, y en los cinco restantes se hace una descripción detallada de las recomendaciones que el Plan realiza para cada uno de los concejos del litoral asturiano siguiendo su distribución geográfica de oeste a este en el territorio de la Autonomía. A mayor abundamiento, dentro del apartado dedicado a cada concejo se especifican las determinaciones aplicables a cada una de las áreas en las que se subdivide. De esta forma, no se hace necesaria la lectura completa del POLA para averiguar las prescripciones aplicables a un municipio costero concreto, sino que es suficiente con acudir al documento propio del municipio para saber el tratamiento dado por el Plan ${ }^{62}$.

El objetivo básico del POLA es, como el de todas las políticas de gestión del litoral, la resolución de la dialéctica utilización-preservación del litoral asturiano. Para llegar a ese entendimiento el Plan emplaza el punto de equilibrio entre ambas visiones en un lugar

\footnotetext{
${ }^{59}$ Ver página anterior.

${ }^{60}$ FERNÁNDEZ HERRERO, J.C. (2007): “La Ordenación y Protección del Litoral Asturiano”, XXXI Curso de Estudios Territoriales y Urbanísticos, pág. 52 y ss.

${ }^{61}$ En este sentido, en el apartado 0.2 de la Memoria del POLA, denominado "Organización del Trabajo", se indica que: "El POLA está organizado teniendo en cuenta su función de instrumento de planeamiento, buscando conseguir a ese efecto la máxima operatividad práctica considerada desde dos aspectos diferentes: permitir que un lector no técnico pueda obtener una fácil comprensión de sus puntos esenciales mediante la lectura de un texto razonablemente breve y permitir que este lector pueda seleccionar con rapidez las propuestas vinculadas a un término municipal costero determinado."

${ }^{62}$ FERNÁNDEZ HERRERO, J.C., loc. cit, pág. 96 y ss.
} 
concreto: potenciando la utilización del litoral pero teniendo siempre como prioridad indiscutible la preservación del mismo. Actuaciones que se llevan a cabo desde las directrices establecidas en el POLA, de manera fundamental, facilitando el acceso y mejorando la calidad del uso recreativo de las zonas litorales. La hoja de ruta marcada por el texto normativo se basa en la idea esencial de que "el conocimiento, el disfrute y el aprecio por los ciudadanos de las cualidades de la costa es una de las mejores garantías para su conservación".

Si procedemos a comparar las medidas propuestas en el POLA con los requerimientos básico que establece la Ley de Costas, nos encontramos con que la norma asturiana excede ampliamente el nivel de protección esencial que señala la ley estatal. Prueba de ello es que el Suelo No Urbanizable de Costas (categoría de suelo específica) ocupa en casi todos los casos una franja de más de 500 metros de ancho.

En relación al tratamiento que el POLA hace del Suelo No Urbanizable de Costas anteriormente introducido, en tanto en cuanto él mismo es el instrumento de desarrollo de las DSOTFC, es el de intentar homogeneizar los diferentes modos en que los variados planeamientos municipales habían gestionado esta categoría de suelo. Para lograr esta armonización se dictan en el Plan una serie de propuestas y criterios que sirven para la delimitación del Suelo No Urbanizable de Costas ${ }^{63}$. Uno de ellas sería la aplicación rigurosa de la distancia legal de 500 metros desde la línea de referencia de la ribera del mar (aunque se posibilita su reducción en los casos de rías y desembocaduras de ríos, excepción no exenta de discusión puesto que significaría el incumplimiento de lo establecido en el TROTU y en las DSOTFC). Otras de las determinaciones es la introducción en la categoría de Suelo No Urbanizable de Costas de aquellas "áreas geográficas homogéneas en sí mismas o dotadas de un carácter propio vinculado a la costa de manera evidente", o el respeto de las delimitaciones de núcleos rurales que hayan sido definidos por los correspondientes planeamientos municipales.

Además de los criterios de delimitación anteriormente reseñados, el POLA propone la elaboración de un Plan Especial del Suelo No Urbanizable de Costas ${ }^{64}$ para facilitar el control urbanístico de estas zonas, en las cuales se localizan multitud de construcciones que no cumplen con lo establecido en la normativa ${ }^{65}$. Bien, pues muy recientemente se ha cumplido este mandato del Plan de Ordenación y con fecha 16 de noviembre de 2016 se ha publicado en el BOPA el Acuerdo de Aprobación Definitiva del Plan Territorial Especial del Suelo No Urbanizable de $\operatorname{Costas}^{66}$ (PESC), tras el Acuerdo positivo adoptado por el Pleno de la Comisión de Urbanismo y Ordenación del Territorio del Principado de Asturias en sesión de 23 de septiembre de 2016 y después de haber recibido, en su período de información pública, 216 alegaciones a su redacción.

El documento del PESC abarca en su regulación un total de 21 concejos costeros, afectando a una superficie de aproximadamente $200 \mathrm{~km}^{2}$. Con base en las clasificaciones establecidas en el POLA, el nuevo Plan Especial va un paso más allá y realiza una zonificación pormenorizada de aquellos terrenos que, dentro del suelo no urbanizable de costas, merecen una protección y categorización específica. Una de las novedades que introduce el PESC, y que consideramos necesario reseñar en este estudio, es la posibilidad de que ciertas edificaciones que se sitúen en zonas no urbanizables de costas puedan cambiar el uso al que están destinadas siempre que se

\footnotetext{
${ }^{63}$ Ver apartado 7.3.1 de la Memoria del POLA.

${ }^{64}$ Ver apartado 7.4 de la Memoria del POLA.

${ }^{65}$ FERNÁNDEZ HERRERO, J.C., loc. cit, pág. 114 y ss.

${ }^{66}$ En atención a lo dispuesto el artículo 53 del TROTU, y en los artículos 103 y siguientes del ROTU.
} 
cumplan con determinados requisitos y adaptaciones establecidas en el articulado del Plan. Se trata de una gran noticia para muchos propietarios, ya que se les abre la posibilidad de acoger, por ejemplo, equipamientos turísticos o dotacionales, algo que hasta este momento estaba prohibido por la normativa ${ }^{67}$.

Finalmente, creemos que es interesante hacer mención de uno de los conceptos más novedosos que introduce el POLA en la ordenación del territorio costero asturiano. Se trata del denominado "parque-playa". Con esta creación urbanística se pretende materializar la solución al dilema utilización-preservación del litoral al que hacíamos referencia al principio de este apartado: se busca hacer compatibles la protección de las playas y el disfrute de las mismas por los ciudadanos. Se trata básicamente de dotar a las playas con zonas de servicios y equipamientos adecuados que se encuentren situadas en su área más cercana pero sin que se invada en ningún caso el propio arenal o su entorno natural, que deben quedar totalmente preservados de cualquier tipo de agresión. Estas zonas de servicios para las playas deben ser terrenos amplios de fácil accesibilidad que, por supuesto, no posean valores naturales dignos de protección.

\subsection{Un ejemplo de la dicotomía desarrollo urbanístico-protección del litoral: el caso del hotel Kaype.}

Hace seis años comenzaba en el municipio de Llanes el caso del hotel Kaype, situado en primera línea de la playa asturiana de Barro. En diciembre de 2012 el consistorio autorizaba la primera de las dos licencias, la de agrupación de fincas, que permitían la ejecución de las obras de ampliación de dicho hotel. Precisamente en esa reagrupación reside la problemática del caso. Dos de los terrenos estaban calificados como urbanos no consolidados, mientras que el tercero de ellos era urbano consolidado. Por esta diferencia de calificaciones surgieron las primeras protestas $y$ denuncias al Ayuntamiento, tanto de colectivos vecinales y particulares como de la Comisión de Urbanismo y Ordenación del Territorio del Principado de Asturias (CUOTA). Con posterioridad se ha conocido que dicha licencia se tramitó en apenas unos días, contando con todos los informes municipales favorables.

En el año 2013 se concedía la licencia de obras y comenzaban los trabajos de ampliación de la edificación por parte de la mercantil Promotora Asturmexicana. A finales del mismo año la CUOTA procedía a emitir un informe en el que señalaba las anomalías que había detectado en ambas licencias, como por ejemplo, el otorgamiento de una edificabilidad mayor que la que debía haber correspondido al proyecto, permitiéndose al mismo una altura superior a las tres plantas. Por su parte, desde la Dirección General de Urbanismo del Principado comunicaron al Ayuntamiento llanisco, en febrero de 2014, que las licencias concedidas adolecían de vicios que comportaban una nulidad de pleno derecho de dichas actuaciones administrativas. A todas estas advertencias se unía, un mes más tarde, el hecho de que la Fiscalía asturiana denunciase al arquitecto municipal por un presunto delito contra la ordenación del territorio cometido en la concesión de la licencia de agrupación de fincas. Y, coincidentemente, en el mes de mayo de ese mismo año se pronunciaba la primera de las sentencias ${ }^{68}$ al respecto de este caso, por la que se anulaba la licencia de agrupación de fincas por tener dichos terrenos naturaleza urbanística distinta. Tras esta anulación el Principado

67 Extraído de la página web del Colegio Oficial de Arquitectos de Asturias: http://www.coaa.es/key/inicio/plan-territorial-especial-del-suelo-no-urbanizable-de-costas-aprobacioninicial_807_2_891_0_1_in.html

${ }^{68}$ Sentencia de 9 de mayo de 2014 del JCA número 3 de Oviedo. 
solicitaba a la Justicia la paralización cautelar de la construcción, decisión que no tardó mucho tiempo en producirse. De hecho, en septiembre se producía el segundo fallo judicial $^{69}$ que anulaba la licencia de obras de la ampliación del hotel, y el día 1 de octubre se ordenaba judicialmente la paralización de las obras.

Las dos anulaciones fueron recurridas ante el Tribunal Superior de Justicia del Principado de Asturias, que en marzo de 2015 emitió su pronunciamiento al respecto. Se ratificaban ambas anulaciones, y para el caso de la licencia de obras fundamentaba la decisión ya no en el exceso de edificabilidad, sino en la ausencia de planeamiento en vigor en el municipio. Tras las elecciones y el cambio en el gobierno municipal, el Ayuntamiento de Llanes presentó ante el JCA número 2 de Oviedo un incidente de nulidad indicando que no era posible el cumplimiento de la sentencia, puesto que la promotora de las obras había solicitado el inicio del procedimiento de legalización de las mismas. La respuesta del Juzgado no se hizo esperar. El 9 de diciembre de 2015 se desestimaba esta petición y se ordenaba proceder a la demolición de todo lo construido en base a las dos licencias que acababan de ser anuladas. El Juzgado ordenaba mediante auto "la completa ejecución de la sentencia y, por tanto, la demolición de las obras amparadas en la licencia anulada".

Cumpliendo con lo dictaminado por la Jueza, se concedieron desde el Ayuntamiento de Llanes las autorizaciones necesarias para que la promotora comenzara a realizar el derribo de la construcción, sin embargo, a finales del mes de diciembre de 2016 se dictaba un informe por el Secretario Municipal en el que se consideraba que parte de los trabajos podían ser legalizados, por lo que el consistorio pedía aclaraciones al respecto al JCA número 2 de Oviedo ${ }^{70}$.

Finalmente, el 24 de enero de 2017, la magistrada del JCA número 2 de Oviedo, dictaba auto en el que ordenaba la demolición inmediata de la ampliación del hotel ${ }^{71}$, y en mayo de ese mismo año comenzaban los trabajos en el terreno. Dos semanas después del inicio del desmantelamiento de la construcción la propiedad y la empresa encargada de los trabajos daban los mismos por concluidos. Sin embargo, en diciembre de 2017 el Juzgado dictaba un nuevo auto en el que señalaba que la demolición no había finalizado aún, puesto que quedaban en pie varias zonas de la ampliación. El propietario del hotel procedió a responder a esta apreciación del Juzgado con un informe técnico en el que se justificaban las estructuras no derribadas con el fin de no perjudicar la estabilidad de la parte legal de la edificación ${ }^{72}$. A la fecha de finalización de este artículo no ha habido aún pronunciamiento definitivo al respecto por parte del JCA nº 2 de Oviedo.

\section{Conclusiones.}

Tras analizar detenidamente los sistemas de gestión y protección del litoral de las Comunidades Autónomas de Andalucía y Principado de Asturias podemos concluir que, sin duda alguna, son muy similares en ciertos aspectos básicos, tales como sus objetivos y fines, y muy diferentes en otros, como por ejemplo la organización y desarrollo de sus instrumentos de planeamiento de las zonas costeras.

\footnotetext{
${ }^{69}$ Sentencia de 17 de septiembre de 2014 del JCA número 2 de Oviedo.

${ }^{70}$ Noticia publicada en el diario El Comercio el día 5 de enero de 2017: "Llanes solicita al juzgado que le indique los pasos a seguir ahora en el "caso Kaype", por Terry Basterra.

${ }^{71}$ Noticia publicada en el diario El Comercio el día 26 de enero de 2017: "La jueza ordena demoler "de forma inmediata" la ampliación del Kaype", por Terry Basterra.

${ }^{72}$ Noticia publicada en el diario El Comercio el día 11 de mayo de 2018: "Kaype, el derribo que no termina", por Lucía Ramos.
} 
Comenzando por la asignación competencial de las funciones de ordenación del territorio, entre las que se incluye la gestión de las zonas costeras que nos ocupa, podemos observar las primeras similitudes. Ambas Comunidades Autónomas asumen esta competencia como exclusiva en sus respectivos Estatutos de Autonomía, encargando el ejercicio de la misma a las correspondientes Consejerías de Medio Ambiente y Ordenación del Territorio, en el caso de Andalucía, y de Infraestructuras, Ordenación del Territorio y Medio Ambiente en el del Principado de Asturias.

Las finalidades que se persiguen con las estrategias asumidas en una y otra Comunidad son, en esencia, las mismas. Como venimos afirmando desde el principio de esta exposición, las políticas sobre el litoral tienen como objetivo el uso racional y sostenible de estos suelos. Su protección y su conservación son prioritarias y deben conjugarse de la manera adecuada con el uso, también necesario, que se haga del litoral; bien lo lleven a cabo ciudadanos, bien sea un uso ejercido por la propia Administración Pública. Consideramos que en ambos sistemas de gestión esta meta preside el conjunto normativo elaborado, si bien es cierto que en el caso de Andalucía sus posibles efectos positivos se ven ampliamente reducidos por la sobreexplotación que se ha producido en algunas de sus áreas (irreversible en ciertos casos) y por lo tardío de su puesta en marcha (el PPCLA es aprobado en el año 2015).

Centrándonos en los instrumentos de planificación elaborados se observa que el Principado de Asturias comenzó a preocuparse por su litoral, y a actuar en consecuencia, unos años antes que la Comunidad Autónoma andaluza. Si bien es cierto que en 1990 se aprobaron en Andalucía las Directrices Regionales del Litoral de Andalucía y se impulsó simultáneamente el Programa de Planeamiento Litoral, ambas iniciativas tuvieron un corto recorrido. La aplicación de ambos instrumentos se paralizó, en gran medida, por el desarrollismo urbanístico que en esos años se estaba produciendo de manera desaforada en la Comunidad Autónoma. A mayor abundamiento, y siguiendo los datos facilitados por el Informe redactado al efecto por el Defensor del Pueblo Andaluz en 1995, la mayoría de los municipios que debían poner en práctica las disposiciones contenidas en las Directrices no conocían su existencia, y los que la conocían, habían omitido poner en práctica aquellas determinaciones que afectaban de manera directa a su planeamiento municipal.

Circunscribiendo nuestro análisis a los instrumentos de planificación realmente efectivos, los planes básicos de ordenación de una y otra Autonomía distan quince años en el tiempo. Las DROT del Principado se aprobaron en 1991, mientras que el POTA no se promulgaría hasta el año 2006. Como resultado, la planificación especial del litoral se retrasaría mucho más en el caso de Andalucía: si las DSOTFC y el POLA se publicaban en el norte en 1993 y 2005, respectivamente, el PPCLA vería la luz muy recientemente, concretamente en el año 2015. Cabe decir a favor de la Comunidad Autónoma andaluza que la longitud de su costa es más del doble que la del Principado de Asturias (945 kilómetros frente a 401 kilómetros), pero, en nuestra opinión, el acelerado desarrollo urbanístico que se viene produciendo desde los años 60 en el litoral andaluz debería haber llamado la atención de sus regidores mucho tiempo atrás.

Por lo que respecta a los dos instrumentos de ordenación y protección del litoral que rigen (o regían, como es el caso de Andalucía tras la anulación del PPCLA) en ambas Comunidades Autónomas cabe señalar varias diferencias significativas. La primera y más notable es la extensión de la servidumbre de protección. Mientras que el PPCLA cumplía estrictamente con lo establecido en la Ley de Costas, el POLA va más allá, introduciendo una "zona de protección específica" de 100 metros que comenzaría en el límite de la zona de servidumbre. Vemos aquí como el Gobierno del Principado ha 
ejercitado su competencia exclusiva y, respetando lo establecido por la norma básica estatal, procede a extender el alcance de su área litoral.

Otra diferencia son los niveles de protección que se instauran. En el caso del PPCLA se definían con claridad tres niveles, a saber: Zonas Litorales de Protección Ambiental, Zonas Litorales de Protección Territorial I y Zonas Litorales de Protección Territorial II. Sin embargo, en el POLA sólo se establece la denominación común Suelo No Urbanizable de Costas, con diferentes subcategorías, tales como el Suelo No Urbanizable de Costas propiamente dicho, el de Reserva de Infraestructuras o el Incluido en Áreas Degradadas por la Edificación. Esta diferencia se explica por el esquema organizativo que presentan ambos planes. El PPCLA hacía una delimitación gráfica de sus zonas de protección mediante la planimetría anexa a su texto, explicando a lo largo de sus normas lo que debe aplicarse en cada nivel de protección. Por el contrario, el POLA especifica concejo por concejo de la geografía asturiana las prescripciones aplicables a cada uno de ellos según sus características propias. Se trata de un sistema organizativo que nos parece mucho más adecuado para el planeamiento del litoral (o de cualquier otro territorio), ya que las circunstancias concretas varían enormemente cuando caminamos sólo unos kilómetros por la zona costera y se hace necesaria, por tanto, una mayor pormenorización de cada área y la normativa a aplicar en la misma. También es cierto que no es una tarea sencilla realizar esta delimitación tan detallada en el caso de una Comunidad Autónoma tan extensa como Andalucía, en la cual muchos municipios necesitarían desarrollar, sólo para su término municipal, un plan propio de protección de su área costera.

Debemos reseñar igualmente que, en nuestra opinión, la reciente aprobación del PESC en la Comunidad Autónoma del Principado de Asturias es un gran acierto. El suelo no urbanizable de costas exige un planeamiento propio e individualizado para garantizar su conservación, atendiendo a las características tan singulares que lo definen. Haciendo una pequeña crítica al contenido del PESC, no consideramos plenamente acertada la medida por la que se posibilita el cambio de uso de las edificaciones situadas en terrenos no urbanizables. Nos preguntamos hasta qué punto puede favorecer a la conservación del entorno natural costero que, por ejemplo, una vivienda familiar pase a ser un hotel, con la consiguiente afluencia de clientes y sus implicaciones, tales como un aumento en la generación de desperdicios o en la contaminación y erosión del lugar.

Para finalizar, y respecto de la reciente anulación del PPCLA, no podemos sino dejar constancia de la clara necesidad de que este vacío normativo sea subsanado con rapidez por las autoridades andaluzas, puesto que la protección del litoral es, tal y como hemos ido relatando a lo largo de este trabajo, una tarea esencial en la conservación de los recursos de nuestro país.

Es evidente que en Andalucía y en el Principado de Asturias se están dando pasos en la buena dirección para proteger nuestras costas, de la misma manera que se está trabajando en ello en el resto de las Autonomías situadas en el litoral español. Aun así, a nuestro parecer, queda aún mucho trabajo por hacer en el ámbito de la gestión integrada de las zonas costeras. 


\section{Bibliografía.}

-ACOSTA BONO, G. (1999): "Ordenación del litoral y política territorial en Andalucía", Actas de las Jornadas sobre el litoral de Almería: caracterización, ordenación y gestión de un espacio geográfico, celebradas en Almería, 20 a 24 de mayo de 1997, págs. 111 - 125.

-BALZA AGUILERA, J., y otros (2013): "La Reforma de la Ley de Costas", Actualidad Jurídica Uría Menéndez, 35-2013, pág. 102.

-BLASCO DÍAZ, J.L., y otros (2010): "La distribución competencial en materia de costas", REAF, № 10, Abril 2010, págs. $245-285$.

-CUESTA REVILLA, J. (2013): “A vueltas con El Algarrobico: la historia interminable de un despropósito medioambiental", Revista Vasca de Administración Pública, N. 99100, págs. $1041-1052$.

-DEFENSOR DEL PUEBLO ANDALUZ (1995): “La ordenación y protección del espacio litoral andaluz: Estudio sobre la posición de las Administraciones Públicas ante el Decreto 118/1990, por el que se aprueban las Directrices Regionales del Litoral de Andalucía."

-FERNÁNDEZ HERRERO, J.C. (2007): "La Ordenación y Protección del Litoral Asturiano”, XXXI Curso de Estudios Territoriales y Urbanísticos, pág. 52 y ss.

-GREENPEACE ESPAÑA, "El Algarrobico" (web en línea):

http://www.greenpeace.org/espana/es/Trabajamos-en/Defensa-de-los-

oceanos/Destruccion-a-toda-costa/Algarrobico/

Consultada el 8 de septiembre de 2018.

-NÚÑEZ LOZANO, M.C. (2015): "El Litoral de Andalucía. Norma y Naturaleza.", Servicio de Publicaciones de la Universidad de Huelva, pág. 261.

-NÚÑEZ LOZANO, M.C. (Dir.) (2016): "Estudios jurídicos sobre el litoral.”, Tirant Lo Blanch.

-PÉREZ GÁLVEZ, J.F. y otros (2013): “Costas y urbanismo: El litoral tras la Ley $2 / 2013$, de protección y uso sostenible del litoral y de modificación de la Ley de Costas.", Wolters Kluwer.

-RANDO BURGOS, E., (2018): "La anulación del Plan de Protección del Corredor Litoral de Andalucía por el Tribunal Superior de Justicia de Andalucía: ¿nuevas dificultades en la planificación territorial de Andalucía?", Revista de Estudios de la Administración Local y Autonómica: Nueva Época, ISSN-e 1989-8975, № 10, 2018, págs. $109-131$.

-RANDO BURGOS, E., (2018): "La atención al medio ambiente desde la ordenación del territorio: una visión general desde el marco legislativo autonómico", Actualidad Jurídica Ambiental, ISSN-e 1989-5666, №. 81, 2018, págs. 121 - 156. 
-SÁNCHEZ GOYANES, E. (Dir.) (2010): “El Derecho de Costas en España”, La Ley Actualidad.

-SANZ LARRUGA, F.J. (2000): "La protección ambiental del litoral español. Hacia una gestión sostenible e integrada de las zonas costeras.", Anuario da Facultade de Dereito da Universidade da Coruña, págs. 459 - 485.

-SANZ LARRUGA, F.J. (2000): "La protección ambiental del litoral español. Hacia una gestión sostenible e integrada de las zonas costeras.", Anuario da Facultade de Dereito da Universidade da Coruña, págs. 459 - 485.

-TORRES ALFOSEA, F.J. (2010): "Cuarenta años de Leyes de Costas en España (1969-2009)”, Investigaciones geográficas, $\mathrm{N}^{\circ}$ 52, Instituto de Geografía de la Universidad de Alicante, pág. 171.

-ZAMORA ROSELLÓ, M.R., (2014): “La protección y uso sostenible del litoral español a la vista de las previsiones comunitarias", Actualidad Administrativa, IX Congreso de la Asociación Española de Profesores de Derecho Administrativo, págs. 1 -2 .

-ZAMORA ROSELLÓ, M.R., (2017): "La sostenibilidad turística a través de los instrumentos andaluces de planificación", Revista Andaluza de Administración Pública, ISSN 1130-376X, Nº. 98, 2017, págs. 395 - 426. 